\title{
"As du Coeur" study: a randomized controlled trial on quality of life impact and cost effectiveness of a physical activity program in patients with cardiovascular disease
}

Laurent Bailly ${ }^{1,2,10^{*}}$ (D), Philippe Mossé ${ }^{3}$, Stéphane Diagana ${ }^{4}$, Marion Fournier ${ }^{2}$, Fabienne d'Arripe-Longueville ${ }^{2}$, Odile Diagana ${ }^{4,5}$, Jocelyn Gal ${ }^{6}$, Jean Grebet ${ }^{7}$, Mario Moncada', Jean-Jacques Domerego ${ }^{8}$, Rémi Radel ${ }^{2}$, Roxane Fabre ${ }^{1,9}$, Alain Fuch ${ }^{5,7}$ and Christian Pradier ${ }^{1,2}$

\begin{abstract}
Background: Physical activity programs (PAP) in patients with cardiovascular disease require evidence of costutility. To assess improvement in health-related quality of life (QoL) and reduction of health care consumption of patients following PAP, a randomized trial was used.

Methods: Patients from a health insurance company who had experienced coronary artery disease or moderate heart failure were invited to participate $(N=1891)$. Positive responders $(N=50)$ were randomly assigned to a progressively autonomous physical activity (PAPA) program or to a standard supervised physical activity (SPA) program. The SPA group had two supervised sessions per week over 5 months. PAPA group had one session per week and support to aid habit formation (written tips, exercise program, phone call). To measure health-related quality of life EQ-5D utility score were used, before intervention, 6 months (T6) and 1 year later. Health care costs were provided from reimbursement databases.
\end{abstract}

Results: Mobility, usual activities and discomfort improved significantly in both group (T6). One year later, EQ-5D utility score was improved in the PAPA group only. Total health care consumption in the intervention group decreased, from a mean of 4097 euros per year before intervention to 2877 euros per year after $(p=0.05)$, compared to a health care consumption of 4087 euros and 4180 euros per year, in the total population of patients ( $N=1891)$ from the health insurance company. The incremental cost effectiveness ratio was 10,928 euros per QALYs.

Conclusion: A physical activity program is cost-effective in providing a better quality of life and reducing health care consumption in cardiovascular patients.

Trial registration: ISRCTN77313697, retrospectively registered on 20 November 2015.

Keywords: Cost-effectiveness, Physical activity, Cardiovascular disease, Quality of life, Health care costs

\footnotetext{
* Correspondence: bailly.!@chu-nice.fr

'Département de Santé Publique, Centre Hospitalier Universitaire de Nice

(Public Health Department University Hospital of Nice), F-06202 Nice, France

¿Université Côte d'Azur, LAMHESS, Nice, France

Full list of author information is available at the end of the article
}

(c) The Author(s). 2018 Open Access This article is distributed under the terms of the Creative Commons Attribution 4.0 International License (http://creativecommons.org/licenses/by/4.0/), which permits unrestricted use, distribution, and reproduction in any medium, provided you give appropriate credit to the original author(s) and the source, provide a link to the Creative Commons license, and indicate if changes were made. The Creative Commons Public Domain Dedication waiver (http://creativecommons.org/publicdomain/zero/1.0/) applies to the data made available in this article, unless otherwise stated. 


\section{Background}

Cardiovascular disease is a burden in France, as in many western countries [1]. Physical activity in patients with cardiovascular disease has been shown to improve exercise capacity and health-related quality of life and to reduce hospital admissions [2]. The aim is to promote the adoption and maintenance [3] of healthful behaviors in cardiovascular patients, notably by supervised physical activity (PA) programs. However, many of those patients do not maintain regular physical activity [4, 5] after program completion. Recent studies have identified habit as the main predictor of physical activity maintenance $[6,7]$. Habit theory assumes that habits are contextdependent, and this might explain why physical activity is difficult to maintain in a patient's "real" living environment after cardiac rehabilitation. While a supervised physical activity program has the advantage of providing a safe environment and social exchange, it cannot reproduce an everyday life context that is characterized by sedentary habits. Thus, a transition between a cardiac rehabilitation program and home-based exercise appears necessary. The "As du Coeur" study is a French monocentric, two-arm, randomized study to compare a standard supervised physical activity program (SPA) and a progressively autonomous physical activity (PAPA) intervention in cardiovascular patients [8]. The first objective of the "As du Coeur study" was to compare the two interventions on physical activity maintenance [9]. The second objective was to establish the cost effectiveness of the program.

Some studies have already shown that cardiac rehabilitation programs significantly reduce health care costs [10-12]. Despite this evidence, health care consumption reduction cannot be directly applied to each country as access to the health care systems and health care consumption vary from one place to another. Therefore, it is important to provide economic evaluation for a physical activity program specifically adapted to cardiovascular patients in France. As a result, the objectives of this study were to establish the cost effectiveness of the French physical activity program "As du Coeur", to evaluate the efficiency of a progressively autonomous versus a standard supervised physical activity program on quality of life improvement, and to ascertain the reduction in health care consumption for cardiovascular patients.

\section{Methods}

This trial, registered as ISRCTN77313697 and approved by the Nice University Hospital ethics committee in 2014 ( $\mathrm{N}^{\circ}$ ID - RCB: 2014-A01559-38), is a French monocentric, two-arm, randomized study to compare a standard supervised physical activity program and a progressively autonomous physical activity intervention in cardiovascular patients. The "As du Coeur" study design, settings and randomization process have already been detailed elsewhere $[8,9]$.

\section{Consent}

Participants were asked to sign a consent form, following a complete explanation of the study, provided in person. They were encouraged to ask questions at this time and were assured of their right not to participate in the study or to withdraw from it at any moment without giving a reason.

\section{Participants}

Cardiovascular patients were identified from the reimbursement database of a health insurance company. Participants had to be over 18 years old, registered with coronary syndrome or heart failure and considered as sedentary according to a brief physical activity assessment [13]. Each participant had to be able to walk at least $250 \mathrm{~m}$ in the six-minute walk test.

The intervention program started in January 2015. Patients of the progressively autonomous physical activity group had two supervised sessions per week for the first 2.5 months, and only one supervised session per week for the last 2.5 months. The supervised physical activity group had two supervised sessions per week over 5 months. The intensity levels were defined in accordance with ACSM guidelines [14]. Autonomous practice was promoted in the progressively autonomous physical activity group with support to aid habit formation: written tips, an exercise program and a calendar [6]. They were called every 2 weeks for a conversation with a researcher trained in habit formation theory.

\section{Quality of life and cost effectiveness evaluation}

Health status was evaluated with the EQ-5D tool [15], a simple, generic measure of health-related quality of life for clinical and economic appraisal [16]. The EQ-5D-3 L descriptive system includes five dimensions and each has three levels: no problems, some problems and extreme problems (Additional file 1). Responses to the questionnaire were mapped to utility weight based on values derived from a representative sample of the French population [17, 18]. In our population, the value of this utility score ranges from 1 , corresponding to perfect health status, to 0.194 .

To estimate life expectancy gain, we used the six-minute walk test, recognized as a valuable independent predictive factor for prognosis in numerous diseases [19-22]. Based on recent published data [19, 20, 23] and selecting the highest threshold of $468 \mathrm{~m}$, our assumption was that a walking distance measured above $468 \mathrm{~m}$ in the six-minute walk test could be considered as a 3 years life expectancy gain in cardiovascular patients.

Program costs were assessed by the time spent by the various stakeholders, cost for patients, and the cost of 
materials. The average program cost per patient was considered as incremental cost. Cost utility was then calculated as incremental cost per Quality Adjusted Life Years (QALYs) gained per patient [24] at 1 year corresponding to average cost per patient of the physical activity program weighted by EQ-5D utility score gain at 1 year.

Health care costs were compared with the total population of cardiovascular patients identified from the reimbursement database. Health care costs for intervention and total population were estimated using costs published by the insurance company.

\section{Statistical analysis}

Continuous variables were expressed as mean and standard deviation (SD) and were compared by Student's $t$ test. Categorical parameters were compared by the Pearson chi-square test or the Fisher exact test. For health care cost comparison and quality of life scores, a normal distribution assumption was verified by graphical tools and statistical tests, i.e., the Shapiro-Wilk and Kolmogorov-Smirnov tests. In the case of a normal distribution assumption, Student's $t$ test or a paired $t$ test was used as appropriate, otherwise the Wilcoxon test was used. For the case of exceptional health care consumption and to avoid biased means, costs above a threshold, fixed to 15 times the median value in the total population, were not taken into consideration.

\section{Results}

Fifty patients were randomly assigned to either the progressively autonomous physical activity (PAPA) program or the supervised physical activity (SPA) program. Five patients were lost to follow-up. Baseline characteristics of the 45 participants are presented in Table 1 . There was no significant difference of age, sex ratio, body mass index, or EQ-5D utility score between PAPA patients and SPA patients. Some differences appeared for the six-minute walk test, as PAPA patients walked a mean distance of $600 \mathrm{~m}$ against $524 \mathrm{~m}$ for SPA patients. Compared to the studies using the six-minute walk test as a prognostic factor [20, 22, 23], at baseline our participants walked a distance corresponding to the highest quartile, similar to those observed in a French population of patients [25] at the end of a cardiac rehabilitation program after an acute coronary syndrome, i.e. 510 to $620 \mathrm{~m}$. At the same time, there were more patients with moderate heart failure and with anticoagulant treatment, in the supervised group. In our population study, most of our patients had a coronary artery disease history without heart failure and were classified in class I or II of the New York Heart Association (NYHA).

\section{Quality of life and cost-utility}

At the end of the intervention, an improvement was observed for health-related quality of life problems measured with the EQ-5D questionnaire. Participants with some or extreme problems decreased significantly compared to baseline, for mobility (from 20.5 to $5.1 \%$ ), usual activities (from 15.9 to $0 \%$ ), and pain or discomfort (from 79.5 to $71.8 \%$ ). The EQ-5D utility score mean was 0.828 in the PAPA group at baseline and 0.891 after intervention and 0.882 at 1 year, corresponding to a gain of 0.054. In the supervised group, the EQ-5D utility score mean was 0.791 at baseline and increased to 0.805 after the intervention, but it decreased to 0.779 at 1 year.

There was an improvement in the walking distance in the six-minute walk test from $561 \mathrm{~m}$ at baseline against $605 \mathrm{~m}$ at T6 $(p<0.001)$. Considering the threshold distance of $468 \mathrm{~m}$ in the six-minute walk test, 38 participants were above it and seven under. The EQ-5D utility score mean was 0.808 in the above $468 \mathrm{~m}$ group before intervention and 0.863 after the physical activity program, corresponding to a gain of 0.055 . At 1 year, there was still a gain in the group walking more than $468 \mathrm{~m}$ as the EQ-5D utility score mean was 0.847 , i.e., +0.039 . On the contrary, in the group walking less than $468 \mathrm{~m}$, the EQ-5D utility score mean was 0.812 before and 0.763 at the end of the intervention, and 0.724 at 1 year.

The cost of the physical activity program per patient was 1279 euros for 5 months. Considering the threshold of a walking distance of $468 \mathrm{~m}$ in the six-minute walk test, an EQ-5D utility score gain of plus 0.039 and a life expectancy of 3 years for the 38 participants concerned, the incremental cost-effectiveness ratio was $10,928 €$ per QALYs. The average incremental cost per patient for the PAPA group was 145 euros, corresponding essentially to 3 one-hour phone sessions with a coach. This incremental cost was divided by the baseline-adjusted incremental QALYs. In the PAPA group the incremental costeffectiveness ratio was 2685 euros per QALYs at 1 year.

\section{Health care costs}

The means of health care costs per year in the total population and in the intervention group, corresponding to the PAPA group and the SPA group, are presented in Table 2. In the total population, the total cost per person was 4087 euros before intervention and 4180 euros during the year of intervention. In the intervention group, while the total health care cost was similar before intervention (i.e., 4097 euros), it significantly $(p=0.05)$ decreased to 2877 euros during the year of intervention. This corresponded to a reduction of nearly $30 \%$. Considering each item separately, we notice a clear decrease of cardiac medications and cardiac visits in the total population and in the intervention group. On the contrary, biological tests and nurse consultations decreased in the intervention group and increased in the total population. 
Table 1 Baseline characteristics

\begin{tabular}{|c|c|c|c|}
\hline & $\begin{array}{l}\text { Progressively autonomous } \\
\text { group }(n=22)\end{array}$ & $\begin{array}{l}\text { Supervised group } \\
(n=23)\end{array}$ & $\mathrm{p}$ \\
\hline Age, mean $\pm S D$ & $62.5 \pm 10.7$ & $63.5 \pm 8.1$ & 0.64 \\
\hline Sex, n (\%) & & & 0.58 \\
\hline Male & $21(95.5)$ & $21(91.3)$ & \\
\hline Female & $1(4.5)$ & $2(8.7)$ & \\
\hline Weight, $\mathrm{kg} \pm \mathrm{SD}$ & $82.4 \pm 13.7$ & $86.8 \pm 12.3$ & 0.27 \\
\hline $\mathrm{BMI}, \mathrm{kg} / \mathrm{m}^{2} \pm \mathrm{SD}$ & $27.1 \pm 4.0$ & $29.5 \pm 4.0$ & 0.07 \\
\hline $\mathrm{AC}, \mathrm{cm} \pm \mathrm{SD}$ & $103.5 \pm 12.3$ & $106.0 \pm 8.7$ & 0.45 \\
\hline $\mathrm{EQ} 5 \mathrm{D}$, mean $\pm \mathrm{SD}$ & $0.828 \pm 0.181$ & $0.791 \pm 0.161$ & 0.48 \\
\hline $6 \mathrm{MWT}$ distance, meters $\pm \mathrm{SD}$ & $600.8 \pm 84.2$ & $524.0 \pm 88.1$ & 0.0064 \\
\hline \multicolumn{4}{|l|}{ NYHA, n (\%) } \\
\hline I & $11(52.4)$ & $6(27.3)$ & \multirow[t]{4}{*}{0.32} \\
\hline$\|$ & $7(33.3)$ & $11(50.0)$ & \\
\hline III & $3(14.3)$ & $4(18.2)$ & \\
\hline IV & - & $1(4.5)$ & \\
\hline \multicolumn{4}{|l|}{ Past medical history, n (\%) } \\
\hline Diabetes & $4(18.2)$ & $3(14.3)$ & 0.73 \\
\hline Hypertension & $6(27.3)$ & $6(26.1)$ & 0.79 \\
\hline Hyperlipidemia & $16(72.7)$ & $15(65.2)$ & 0.59 \\
\hline Moderate heart failure & $1(4.5)$ & $7(33.3)$ & 0.0212 \\
\hline Myocardial infarction & $5(22.7)$ & $9(40.9)$ & 0.19 \\
\hline \multicolumn{4}{|l|}{ Revascularization, n (\%) } \\
\hline Angioplasty & $15(68.2)$ & $13(56.5)$ & 0.42 \\
\hline CABG & $3(13.6)$ & $4(19.0)$ & 0.70 \\
\hline \multicolumn{4}{|l|}{ Cardiac function, n (\%) } \\
\hline LVEF $<50 \%$ & $1(4.8)$ & $3(14.3)$ & 0.13 \\
\hline LVEF > 50\% & $20(95.2)$ & $18(85.7)$ & \\
\hline Current smokers, n (\%) & $4(18.2)$ & $3(14.3)$ & 0.73 \\
\hline \multicolumn{4}{|l|}{ Drugs, n (\%) } \\
\hline Antiplatelet drugs & 19 (86.4) & $16(69.6)$ & 0.17 \\
\hline Anticoagulants & - & $4(19.0)$ & 0.0485 \\
\hline Beta-blockers & $11(50.0)$ & $11(47.8)$ & 0.88 \\
\hline
\end{tabular}

Abbreviations: AC Abdominal circumference, BMI Body Mass Index, CABG Coronary artery bypass graft, LVEF Left ventricular ejection fraction, $6 M W T$ Six-minute walk test, $S D$ Standard deviation

\section{Discussion}

Our study suggests a significant reduction of health care consumption after a physical activity program in patients with cardiovascular disease. It also confirmed our hypothesis that an intervention for people with cardiovascular disease that promotes habit formation in an everyday life context, will result in better maintenance of quality of life.

The comparison of the progressively autonomous physical activity (PAPA) against the standard supervised physical activity (SPA) programs, using the EQ-5D utility score shows that health-related quality of life maintenance at 1 year was observed only in the PAPA group. Our physical activity program appeared to be cost effective, in providing a better quality of life in cardiovascular patients able to walk more than $468 \mathrm{~m}$ in the six-minute walk test. The EQ-5D utility score means were improved in participants walking more than $468 \mathrm{~m}$ in the six-minute walk test, from 0.808 at baseline to 0.863 after the physical activity program, to 0.847 at 1 year. The gains of plus 0.055 after the physical activity program and plus 0.039 at 1 year are in line with those minimum clinical differences. Goldsmith et al. [26] studied the relationship between measures used in studies of cardiac disease and the EQ-5D 
Table 2 Health care costs means in euros per year and per person

\begin{tabular}{|c|c|c|c|c|c|c|c|c|}
\hline & \multicolumn{2}{|c|}{ Total population } & \multirow[b]{2}{*}{$p$} & \multirow[b]{2}{*}{$\%^{a}$} & \multirow[b]{2}{*}{$\begin{array}{l}2013-2014 \\
(N=43)\end{array}$} & \multicolumn{2}{|c|}{ Intervention group } & \multirow[b]{2}{*}{$\%^{a}$} \\
\hline & $\begin{array}{l}2013-2014 \\
(N=1891)\end{array}$ & $\begin{array}{l}2015 \\
(N=1891)\end{array}$ & & & & $\begin{array}{l}2015 \\
(N=43)\end{array}$ & $p$ & \\
\hline Hospital & 2447.5 & 2169.0 & 0.61 & $-11,4 \%$ & 1970.1 & 872.2 & 0.12 & $-55,7 \%$ \\
\hline Cardiac medications & 431.4 & 339.7 & $<0.001$ & $-21,3 \%$ & 523.3 & 398.3 & $<0.001$ & $-23,9 \%$ \\
\hline Other drugs & 751.7 & 678.9 & $<0.001$ & $-9,7 \%$ & 694.1 & 643.7 & 0.25 & $-7,3 \%$ \\
\hline Cardiac visits & 99.4 & 85.9 & $<0.001$ & $-13,6 \%$ & 91.7 & 71.7 & 0.0168 & $-21,8 \%$ \\
\hline General practitioner & 244.1 & 277.3 & $<0.001$ & $+13,6 \%$ & 210.7 & 239.5 & 0.08 & $+13,7 \%$ \\
\hline Specialist visits & 135.2 & 141.6 & 0.35 & $+4,7 \%$ & 125.5 & 137.4 & 0.79 & $+9,5 \%$ \\
\hline Biological tests & 175.8 & 224.3 & $<0.001$ & $+27,6 \%$ & 207.7 & 162.4 & 0.13 & $-21,8 \%$ \\
\hline Nurse consultations & 205.6 & 219.3 & 0.51 & $+6,7 \%$ & 268.5 & 201.6 & 0.0216 & $-24,9 \%$ \\
\hline Investigations & 526.0 & 537.1 & 0.92 & $+2,1 \%$ & 696.4 & 668.1 & 0.84 & $-4,1 \%$ \\
\hline Total & $4087.3 €$ & $4179.9 €$ & 0.41 & $+2,3 \%$ & $4096.7 €$ & $2877.0 €$ & 0.05 & $-29,8 \%$ \\
\hline
\end{tabular}

${ }^{a}$ Health care consumption evolution between years 2013-2014 and year 2015

index. The authors concluded that the minimum clinically important difference of a one-minute increase in treadmill exercise time was associated with a 0.019 increase in the EQ-5D index, and a 10 unit increase in Seattle Angina Questionnaire (SAQ) scales was associated with an increase between 0.04 and 0.07 in EQ-5D. Recent large trials in patients with heart failure have shown that health-related quality of life values were independently associated with long-term cardiovascular morbidity and mortality, and notably EQ-5D utility score [27, 28]. Ambrosy et al. have shown a $20 \%$ increased risk of death or hospitalization for a decrease of 0.1 units in baseline EQ-5D utility score.

The EQ-5D utility score means decreased in the seven participants walking less than $468 \mathrm{~m}$ in the six-minute walk test. For those patients, the physical activity program was clearly not cost effective, suggesting the need to raise the usually retained threshold, $250 \mathrm{~m}$, from a cost effectiveness point of view. Gusi et al. [29] have already shown that the baseline level of the six-minute walk test could predict the magnitude of quality of life changes.

The incremental cost effectiveness ratio was of 10,928 euros per Quality Adjusted Life Years, which is under the threshold usually retained [30,31] for a gain of one QALY. Miller et al. [32] reported median values per QALY by category of cardiovascular disease studies, published between 2000 and 2011. Values range from 22,113 to 49,637 dollars (19,485 to 43,743 euros), respectively for coronary heart disease and congestive heart failure treatment.

At the same time, total health care consumption showed a clear decrease after the intervention, from 4097 euros to 2877 euros, whereas there was no difference in consumption among the total population of patients invited to participate in this physical activity program, i.e., from 4087 euros to 4180 euros. The total health care consumption mean difference, i.e. 1220 euros, corresponds to the cost of the physical activity program for one patient, i.e. 1279 euros.

We have shown that patients following a progressively autonomous physical activity program had a better EQ-5D utility score mean at 1 year from the intervention, compared to patients with standard supervised physical activity program. Respectively, the index values were 0.882 in the progressively autonomous group and 0.779 in the supervised group at 1 year. The supplementary cost in the progressively autonomous group was essentially due to phone contact with the group coach for follow-up. The phone call for quality of life improvement at 1 year is well worth the cost, as the call cost only 145 euros per patient out of an average total cost of 1279 euros.

Our study has some limitations. Although the hypothesis of our study for health care consumption reduction has been confirmed, the relative low number of participants and the voluntary-based recruitment, for a five-month long physical activity program without interruption, leads us to consider prudently the extrapolation to other populations of the total health care consumption reduction observed in our study.

Another limit of our study could be that the estimation of life expectancy gain, after a physical activity program in cardiovascular patients, is grounded on hypothesis rather than on direct observation. However, our choice (3 years gains) is conservative and the threshold, to be considered as a 3 years life expectancy gain in cardiovascular patients, is high $[19,23]$. Moreover, Hage et al. [33] studied physical activity level and health related quality of life three to 6 years after a myocardial infarction in elderly Sweden patients. They concluded that after a coronary event, a supervised physical activity 
program has the potential to positively influence activity and quality of life for as long as three to 6 years.

\section{Conclusion}

To conclude, our study has shown first, that a physical activity program is cost effective, providing a better quality of life in patients with coronary artery disease or moderate heart failure history, for a reasonable cost corresponding to the health care consumption reduction observed 1 year after the intervention, and second, that a PAPA program is more efficient than a SPA program on quality of life improvement.

\section{Additional file}

Additional file 1: Questionnaires used in the «As du coeur » study. (PDF $558 \mathrm{~kb}$ )

\section{Abbreviations}

EQ-5D: European Quality in 5 Dimensions; NYHA: New York Heart Association; PA: Physical activity; PAPA: Progressively Autonomous Physical Activity; QALYs: Quality Adjusted Life Years; SAQ: Seattle Angina Questionnaire; SPA: Supervised Physical Activity; T0: At baseline; T12: At 1 year after the beginning of the intervention (12 months); T6: After the physical activity program (6 months)

\section{Acknowledgements}

The authors want to thank all participants to the As du Coeur study for their involvement during the study and especially the association of patients "As Coeur Santé 06". The authors want to thank all the investigators of the study and particularly the physical activity coaches. The authors want to thank Melissa Diagana for her careful reading and constructive advices. The authors want to thank the Régime Social des Indépendants Côte d'Azur, Diagana Sport Santé, Malakoff Médéric, Mutuelles du Soleil, Fondation du sport française, Fondation Française Des Jeux, the hospital "Les Sources", the Public Health Department of the Nice University Hospital and the LAMHESS of Nice Côte d'Azur University, and all members of the "Azur Sport Santé" for their help and their involvement. The authors would also like to thank the "Agence Régionale de Santé Provence Alpes Côte d'Azur" for its support.

\section{Funding}

The "Agence Régionale de Santé Provence Alpes Côte d'Azur", "Malakoff Médéric", "Mutuelles du Soleil," the "Française des Jeux" Foundation, the "Sécurité Sociale des Indépendants" and a CIFRE fellowship from the "Association Nationale de la Recherche et de la Technologie" and "Diagana Sport Santé" supported financially the study. The "Agence Régionale de Santé Provence Alpes Côte d'Azur", "Malakoff Médéric", "Mutuelles du Soleil," the "Française des Jeux" Foundation, the "Sécurité Sociale des Indépendants" and a CIFRE fellowship from the "Association Nationale de la Recherche et de la Technologie" and "Diagana Sport Santé" supported financially the study but did not have any role in study design.

\section{Availability of data and materials}

Data is available from the authors on reasonable request.

\section{Sources of support}

The "Agence Régionale de Santé Provence Alpes Côte d'Azur", "Malakoff Médéric", "Mutuelles du Soleil," the "Française des Jeux" Foundation, the "Sécurité Sociale des Indépendants" and a CIFRE fellowship from the "Association Nationale de la Recherche et de la Technologie" and "Diagana Sport Santé." supported financially the study.

\section{Authors' contributions}

The protocol was developed by MF, RR, Fd'A-L. AF, SD, OD, JG, JG, MM, J-JD made substantial contributions to conception, design and acquisition of data. LB, PM, RF, CP made substantial contributions to analysis, interpretation of data, prepared the initial manuscript, involved in drafting the manuscript and revising it critically for important intellectual content. All authors reviewed the final manuscript prior to submission. All authors read and approved the final manuscript.

\section{Ethics approval and consent to participate}

This trial, has been approved by the Nice University Hospital ethics committee in 2014 (N ID - RCB: 2014-A01559-38). The participant consent was written

\section{Consent for publication}

Not applicable.

\section{Competing interests}

The authors declare that they have no competing interests.

\section{Publisher's Note}

Springer Nature remains neutral with regard to jurisdictional claims in published maps and institutional affiliations.

\section{Author details}

${ }^{1}$ Département de Santé Publique, Centre Hospitalier Universitaire de Nice (Public Health Department University Hospital of Nice), F-06202 Nice, France. ${ }^{2}$ Université Côte d'Azur, LAMHESS, Nice, France. ${ }^{3}$ LEST, Aix-Marseille Université, CNRS, Aix en Provence, France. ${ }^{4}$ Diagana Sport Santé, Nice, France. ${ }^{5}$ Azur Sport Santé, Nice, France. ${ }^{6}$ Epidemiology and Biostatistics Unit, Centre Antoine Lacassagne, Nice, France. ${ }^{7}$ Sécurité Sociale des Indépendants, Nice, France. ${ }^{8}$ Hôpital Privé Gériatrique les Sources, Nice, France. ${ }^{9}$ EA Cobtek, University of Nice Sophia-Antipolis, Nice, France. ${ }^{10}$ Département de Santé Publique, CHU Nice, Hôpital Archet 1. Niveau1 151 Route Saint Antoine de Ginestière CS 23079, 06202 Nice Cedex 3, France.

Received: 13 April 2018 Accepted: 28 November 2018

Published online: 06 December 2018

\section{References}

1. WHO | Health in 2015: from MDGs to SDGs [Internet]. WHO. [cited 2017 Jul 18]. Available from: http://www.who.int/gho/publications/mdgs-sdgs/en/.

2. Anderson L, Taylor RS. Cardiac rehabilitation for people with heart disease: an overview of Cochrane systematic reviews. Cochrane Database Syst Rev. 2014:12(12):CD011273.

3. Pinto BM, Goldstein MG, Papandonatos GD, Farrell N, Tilkemeier P, Marcus $\mathrm{BH}$, et al. Maintenance of exercise after phase II cardiac rehabilitation: a randomized controlled trial. Am J Prev Med. 2011;41(3):274-83.

4. Kotseva K, Wood D, De Backer G, De Bacquer D, EUROASPIRE III Study Group. Use and effects of cardiac rehabilitation in patients with coronary heart disease: results from the EUROASPIRE III survey. Eur J Prev Cardiol. 2013;20(5):817-26.

5. J-AD C. Systematic review of physical activity intervention studies after cardiac rehabilitation. J Cardiovasc Nurs. 2011;26(5):351-8.

6. Gardner B, Lally P, Wardle J. Making health habitual: the psychology of "habit-formation" and general practice. Br J Gen Pract J R Coll Gen Pract. 2012;62(605):664-6.

7. Rothman AJ, Sheeran P, Wood W. Reflective and automatic processes in the initiation and maintenance of dietary change. Ann Behav Med Publ Soc Behav Med. 2009;38(Suppl 1):S4-17.

8. Fournier M, Radel R, Tifratene K, Pradier C, Fuch A, Mossé P, et al. Protocol of the "As du Coeur" study: a randomized controlled trial on physical activity maintenance in cardiovascular patients. BMC Cardiovasc Disord. 2016;16(1):160.

9. Fournier M, Radel R, Bailly L, Pradier C, Fabre R, Fuch A, et al. "As du Coeur" study: a randomized controlled trial on physical activity maintenance in cardiovascular patients. BMC Cardiovasc Disord. 2018;18(1):77.

10. Ades PA, Huang D, Weaver SO. Cardiac rehabilitation participation predicts lower rehospitalization costs. Am Heart J. 1992:123(4 Pt 1):916-21.

11. Ades PA, Pashkow FJ, Nestor JR. Cost-effectiveness of cardiac rehabilitation after myocardial infarction. J Cardpulm Rehabil. 1997;17(4):222-31.

12. Yu C-M, Lau C-P, Chau J, McGhee S, Kong S-L, BM-Y C, et al. A short course of cardiac rehabilitation program is highly cost effective in improving longterm quality of life in patients with recent myocardial infarction or 
percutaneous coronary intervention. Arch Phys Med Rehabil. 2004;85(12): 1915-22.

13. Marshall AL, Smith BJ, Bauman AE, Kaur S. Reliability and validity of a brief physical activity assessment for use by family doctors. Br I Sports Med. 2005; 39(5):294-7 discussion 294-297.

14. Medicine AC of S. ACSM's Guidelines for Exercise Testing and Prescription. Lippincott Williams \& Wilkins; 2013. 481 p.

15. EuroQol Group. EuroQol--a new facility for the measurement of healthrelated quality of life. Health Policy Amst Neth. 1990;16(3):199-208.

16. Coca Perraillon M, Shih $\mathrm{Y}-\mathrm{CT}$, Thisted RA. Predicting the EQ-5D-3L preference index from the SF-12 health survey in a national US sample: a finite mixture approach. Med Decis Mak Int J Soc Med Decis Mak. 2015; 35(7):888-901.

17. Szende A, Oppe M, Devlin N. EQ-5D value sets: inventory, comparative review and user guide. Eds. EuroQol Group Monograph series: Vol. 2. Netherlands: Springer; 2006.

18. Chevalier J, de Pouvourville G. Valuing EQ-5D using time trade-off in France. Eur J Health Econ HEPAC Health Econ Prev Care. 2013;14(1):57-66.

19. Beatty AL, Schiller NB, Whooley MA. Six-minute walk test as a prognostic tool in stable coronary heart disease: data from the heart and soul study. Arch Intern Med. 2012;172(14):1096-102.

20. Guazzi M, Dickstein K, Vicenzi M, Arena R. Six-minute walk test and cardiopulmonary exercise testing in patients with chronic heart failure: a comparative analysis on clinical and prognostic insights. Circ Heart Fail. 2009;2(6):549-55.

21. Spruit MA, Polkey MI, Celli B, Edwards LD, Watkins ML, Pinto-Plata V, et al. Predicting outcomes from 6-minute walk distance in chronic obstructive pulmonary disease. J Am Med Dir Assoc. 2012;13(3):291-7.

22. Kohl L de M, Signori LU, Ribeiro RA, Silva AMV, Moreira PR, Dipp T, et al. Prognostic value of the six-minute walk test in end-stage renal disease life expectancy: a prospective cohort study. Clin Sao Paulo Braz. 2012;67(6):581-6.

23. Wegrzynowska-Teodorczyk K, Rudzinska E, Lazorczyk M, Nowakowska K, Banasiak W, Ponikowski P, et al. Distance covered during a six-minute walk test predicts long-term cardiovascular mortality and hospitalisation rates in men with systolic heart failure: an observational study. J Physiother. 2013; 59(3):177-87.

24. Torrance GW, Feeny D. Utilities and quality-adjusted life years. Int J Technol Assess Health Care. 1989;5(4):559-75.

25. Gremeaux V, Troisgros O, Benaïm S, Hannequin A, Laurent Y, Casillas J-M, et al. Determining the minimal clinically important difference for the sixminute walk test and the 200-meter fast-walk test during cardiac rehabilitation program in coronary artery disease patients after acute coronary syndrome. Arch Phys Med Rehabil. 2011;92(4):611-9.

26. Goldsmith KA, Dyer MT, Schofield PM, Buxton MJ, Sharples LD. Relationship between the EQ-5D index and measures of clinical outcomes in selected studies of cardiovascular interventions. Health Qual Life Outcomes. 2009;7:96.

27. Ambrosy AP, Hernandez AF, Armstrong PW, Butler J, Dunning A, Ezekowitz $J A$, et al. The clinical course of health status and association with outcomes in patients hospitalized for heart failure: insights from ASCEND-HF. Eur J Heart Fail. 2016;18(3):306-13.

28. Ambrosy AP, Cerbin LP, DeVore AD, Greene SJ, Kraus WE, O'Connor CM, et al. Aerobic exercise training and general health status in ambulatory heart failure patients with a reduced ejection fraction-findings from the heart failure and a controlled trial investigating outcomes of exercise training (HF-ACTION)trial. Am Heart J. 2017;186:130-8.

29. Gusi N, Hernandez-Mocholi MA, Olivares PR. Changes in HRQoL after 12 months of exercise linked to primary care are associated with fitness effects in older adults. Eur J Pub Health. 2015;25(5):873-9.

30. McCabe C, Claxton K, Culyer AJ. The NICE cost-effectiveness threshold: what it is and what that means. PharmacoEconomics. 2008;26(9):733-44.

31. Claxton K, Martin S, Soares M, Rice N, Spackman E, Hinde S, et al. Methods for the estimation of the National Institute for health and care excellence cost-effectiveness threshold. Health Technol Assess Winch Engl. 2015;19(14): $1-503 \mathrm{v}-\mathrm{vi}$.

32. Miller G, Cohen JT, Roehrig C. Cost-effectiveness of cardiovascular disease spending. J Am Coll Cardiol. 2012;60(20):2123-4.

33. Hage C, Mattsson E, Ståhle A. Long-term effects of exercise training on physical activity level and quality of life in elderly coronary patients-a three- to six-year follow-up. Physiother Res Int J Res Clin Phys Ther. 2003;8(1):13-22.

Ready to submit your research? Choose BMC and benefit from:

- fast, convenient online submission

- thorough peer review by experienced researchers in your field

- rapid publication on acceptance

- support for research data, including large and complex data types

- gold Open Access which fosters wider collaboration and increased citations

- maximum visibility for your research: over $100 \mathrm{M}$ website views per year

At BMC, research is always in progress.

Learn more biomedcentral.com/submissions 